Monika Szturmowicz', Aneta Kacprzak', Dorota Wyrostkiewicz', Katarzyna Lewandowska', Małgorzata Jędrych', Iwona Bartoszuk', Jarosław Kober², Barbara Burakowska², Inga Barańska², Grzegorz Małek², Jan Kuś

${ }^{1} 1^{\text {st }}$ Department of Lung Diseases, National Tuberculosis and Lung Diseases Research Institute, Warsaw, Poland

${ }^{2}$ Department of Radiology, National Tuberculosis and Lung Diseases Research Institute, Warsaw, Poland

\title{
Non-high risk PE in the patients with acute or exacerbated respiratory disease: the value of the algorithm based on D-dimer evaluation and Revised Geneva Score
}

The authors declare no financial disclosure

\begin{abstract}
Introduction: The diagnostic algorithm of non-high risk pulmonary embolism (PE) is based on probability scoring systems and plasma D-dimer (DD) assessment. The aim of the present study was to investigate the efficacy of Revised Geneva Scoring (RGS) and $\mathrm{DD}$ testing for the excluding of non-high risk $\mathrm{PE}$, in the patients admitted to the hospital due to acute respiratory diseases. Material and methods: The consecutive patients, above 18 years of age, referred to the department of lung diseases, entered the study. The exclusion criteria were: the pregnancy and the suspicion of high risk PE. Plasma DD was measured with quick ELISA test, VIDAS D-dimer New, bioMerieux, France. Multislice computed tomography angiography was performed in all of the patients. Results: 153 patients, median age $65(19-88)$ years entered the study. The probability of PE was: low — in 58 patients $(38 \%)$, intermediate - in $90(59 \%)$, high — in $5(3 \%)$. DD $<500 \mathrm{ng} / \mathrm{ml}$ was found in $12 \%$ of patients with low and intermediate probability of PE. PE was recognized in 10 out of 153 patients (7\%). None of the patients with $\mathrm{DD}<500 \mathrm{ng} / \mathrm{ml}$ was diagnosed with PE (NPV 100\%). Median DD value was significantly higher in PE patients comparing to non-PE $(4500 \mathrm{ng} / \mathrm{ml}$ and $1356 \mathrm{ng} / \mathrm{ml}$ respectively, $\mathrm{p}=0.006$ ).

Conclusion: In the group of the patients with acute respiratory symptoms, low or intermediate clinical probability scoring combined with normal DD had a high NPV in excluding PE. Nevertheless, such approach was not very effective, as the increased DD was noted in $88 \%$ of the examined population.
\end{abstract}

Key words: d-dimer, pulmonary embolism, probability assessment, respiratory diseases

Pneumonol Alergol Pol 2015; 83: 445-452

\section{Introduction}

Venous thromboembolic disease (VTE) is a common and potentially life threatening disease, with the incidence rate of 100-200/100 000 in Europe and in the United States of America [1, 2]. The risk factors, such as: previous episodes of deep vein thrombosis, immobilization, trauma, neoplastic disease, markedly increase the probability of VTE
[3-5]. According to recent publications, incidence of VTE is also increased in the patients with chronic lung disorders, such as: chronic obstructive pulmonary disease (COPD) [6], severe asthma [7], idiopathic pulmonary fibrosis [8] and sarcoidosis $[9,10]$.

The diagnostic algorithm of non-high risk PE is based on probability scoring systems, such as Wells Score or Revised Geneva Score (RGS) [11]. In the patients with low and intermediate probability

Address for correspondence: Prof. Monika Szturmowicz, MD, PhD, I Department of Lung Diseases, National Institute of Tuberculosis and Lung Diseases, Warsaw, Poland, ul. Płocka 26, 01-138 Warszawa, e-mail: monika.szturmowicz@gmail.com DOI: 10.5603/PiAP2015.0073

Received: 28.08.2015

Copyright (C) 2015 PTChP

ISSN 0867-7077 
of PE, plasma D-dimer (DD) evaluation is the next diagnostic step, according to ESC guidelines [11]. The quantitative DD tests based on enzyme-linked immunosorbent assays are recommended for this procedure [11]. Normal D-dimer concentration $(<$ $500 \mathrm{ng} / \mathrm{mL}$ ) in the patient with low or intermediate probability of PE has high negative predictive value (NPV) for VTE [12]. The risk of PE development in such population is less than $1 \%$ in 3 months of subsequent follow up [12].

$\mathrm{DD}$ is a non-specific marker indicating the activation of the process of fibrin turnover. Elevated DD concentrations were reported in pregnancy, pneumonia, sepsis, Alzheimer's disease, arterial thrombosis, and malignancy [13-15]. Moreover DD level correlates with age and increases in the patients above 50 years of age [16, 17]. Recently, Schouten et al. proposed the age adjusted DD cut off (age $\times 10$ $\mathrm{ng} / \mathrm{mL}$ ) [18]. The authors of the ADJUST-PE study found that age-adjusted DD threshold is combined with improvement of specificity without loosing of the sensitivity of the model of PE prediction based on clinical probability and DD [19]. Nevertheless, according to Woller et al. further validation is needed to finally approve such diagnostic approach [20]. Renal insufficiency may also influence DD concentration, but the increase of DD in the patients with GRF $30-60 \mathrm{~mL} / \mathrm{min}$ is moderate [21].

The value of PE diagnostic algorithm based on probability scoring and DD was not investigated extensively in the patients with acute or exacerbated respiratory diseases. Thus the aim of the present study was to investigate the efficacy of RGS and DD testing for the excluding of non-high risk $\mathrm{PE}$, in the patients admitted to the hospital due to acute respiratory symptoms.

\section{Material and methods}

The consecutive patients, above 18 years of age, referred in 2013 to the $\mathrm{I}^{\text {st }}$ Department of Lung Diseases of the National Institute of Tuberculosis and Lung Diseases in Warsaw due to acute respiratory symptoms, entered the study. The exclusion criteria were: the pregnancy and the suspicion of high risk PE, based on the signs of shock or significant hypotension defined as the decrease of systolic blood pressure to the value below $90 \mathrm{~mm} \mathrm{Hg}$ or greater than $40 \mathrm{~mm} \mathrm{Hg}$, for at least 15 minutes [10].

The PE probability was assessed with RGS (Table 1). Plasma DD was measured in all of the patients, on 1-3 hospital day, with quick ELISA test, VIDAS D-dimer New, bioMerieux, France. Threshold value for DD was $500 \mathrm{ng} / \mathrm{mL}$ according to manufacturer's recommendations.
Multislice computed tomography angiography (CTA) was performed in all of the patients with a 16-detector scanner (Siemens Somatom Sensation 16) according to "pulmonary embolism" protocol. $80 \mathrm{~mL}$ of low osmotic, iodine contrast medium was used (intravenous injection, with an automatic syringe).

The following clinical and laboratory parameters were recorded: dyspnea, chest pain, hemoptysis, cough, purulent expectoration, increased body temperature on admission ( $>$ $38^{\circ} \mathrm{C}$ ), morphological blood analysis, CRP, and blood gas analysis.

\section{Statistical analysis}

A database and all analyses were performed using STATISTICA 6.0 (Statsoft) computer software. The results were expressed as median values and ranges. For comparison of categorical variables between the groups - the Fisher test was used, for continuous variables - U Mann-Whitney and Kruskal-Wallis tests were applied. P-value $<0.05$ was considered statistically significant.

\section{Results}

153 patients (84 males and 69 females), median age 65 (19-88) years entered the study. Clinical characteristics of the study population is presented in Table 2. Most frequent complaints

Table 1. Revised Geneva Scoring

\begin{tabular}{lc}
\hline \multicolumn{1}{c}{ Variables } & Points \\
\hline Predisposing factors & 1 \\
age $>65$ years & 3 \\
Previous DVT or PE & 2 \\
$\begin{array}{l}\text { Surgery of fracture within one } \\
\text { month }\end{array}$ & \\
Active malignancy & 2 \\
Symptoms & \\
Unilateral lower limb pain & 3 \\
Hemoptysis & 2 \\
Clinical signs & \\
$\begin{array}{l}\text { Heart rate } \\
75 \text { to } 94 \text { per minute }\end{array}$ & \\
$\geq 95$ per minute & 3 \\
Pain on lower limb deep & 5 \\
vein palpation or unilateral & 4 \\
0edema & \\
Clinical probability & Low: $0-3$ point, intermediate: \\
& $4-10$ points, High: $\geq 11$ points \\
\hline
\end{tabular}


Table 2. Clinical characteristics of the examined population and comparison of PE and non-PE patients (pts)

\begin{tabular}{lcccc}
\hline Clinical characteristics & $\begin{array}{c}\text { Total } \\
\text { No 153 }\end{array}$ & $\begin{array}{c}\text { PE pts } \\
\text { No 10 }\end{array}$ & $\begin{array}{c}\text { Non-PE pts } \\
\text { No 143 }\end{array}$ & $\begin{array}{c}\text { P } \\
\text { PE vs. non PE }\end{array}$ \\
\hline Age (median, range) & $65.0(19.0-88.0)$ & $65.5(43.0-81.0)$ & $65.0(19.0-88.0)$ & 0.85 \\
Gender males/females & $84 / 69(54.9 / 45.1 \%)$ & $7 / 3(70 / 30 \%)$ & $77 / 66(53.8 / 46.1 \%)$ & 0.51 \\
Dyspnea $\mathrm{n}(\%)$ & $111(72.5)$ & $8(80.0)$ & $103(72.0)$ & 0.73 \\
Chest pain $\mathrm{n}(\%)$ & $38(24.8)$ & $5(50.0)$ & $33(23.1)$ & 0.12 \\
Cough $\mathrm{n}(\%)$ & $107(69.9)$ & $6(60.0)$ & $101(70.6)$ & 0.49 \\
Hemopthysis $\mathrm{n}(\%)$ & $31(20.3)$ & $2(20.0)$ & $29(20.3)$ & 1.0 \\
Purulent sputum $\mathrm{n}(\%)$ & $24(15.7)$ & $0(0.0)$ & $24(16.8)$ & 0.36 \\
Temp $>38{ }^{\circ} \mathrm{C}$ & $41(26.8)$ & $2(20.0)$ & $39(27.3)$ & 1.0 \\
VTE med. hist. $\mathrm{n}(\%)$ & $15(9.8)$ & $3(30.0)$ & $12(8.4)$ & 0.06 \\
Risk factors $\mathrm{n}(\%)$ & $35(22.9)$ & $3(30.0)$ & $32(22.4)$ & 0.7 \\
Revised Geneva Score (median) & $4(0-11)$ & $4.5(0-11)$ & $4.0(0-11)$ & 0.92 \\
\hline
\end{tabular}

PE — pulmonary embolism; VTE — venous thromboembolic disease

were: dyspnea (72\%) and cough (69.9\%). Hemoptysis and pleuritic chest pain were found in $20 \%$ and $24.8 \%$ of patients respectively.

RGS revealed low probability of PE - in 58 patients (38\%), intermediate probability - in 90 (59\%) and high probability - in 5 (3\%). DD $<500$ $\mathrm{ng} / \mathrm{mL}$ was found in 18 out of 148 patients with low and intermediate probability of PE (12\%): in $3 / 58$ of patients with low probability of PE (5\%) and in $15 / 90$ of patients with intermediate probability of PE (16\%).

PE based on CTA was recognized in 10 out of 153 patients (7\%): 4/58 (7\%) of low probability population, 4/90 (4\%) of intermediate probability and $2 / 5(40 \%)$ of high probability. The thrombi were localized in lobar pulmonary arteries - $(2$ patients), in segmental pulmonary arteries - (3 patients), both lobar and segmental — pulmonary arteries - (4 patients), sub-segmental arteries (1 patient). Radiological signs of lung infarcts and/ or pleural fluid were found in 2 patients. In 7 out of $10 \mathrm{PE}$ patients other pathology was additionally diagnosed: lung cancer - in 2 patients, pneumonia, COPD, sarcoidosis, idiopathic lung fibrosis and heart insufficiency - in 1 patient each.

The final diagnosis in those patients in whom PE was excluded was: neoplastic disease of the chest (lung cancer, thymoma, mesothelioma) — in 45 patients (pts), community acquired pneumonia (CAP) - in 18 pts, exacerbation of asthma or COPD - in 15 pts, idiopathic pulmonary fibrosis (IPF) - in 10 pts, other interstitial lung disease - in 19 pts, infective exacerbation of cystic fibrosis (CF) or non-CF bronchiectasis - in 11 pts, organizing pneumonia (OP) or bronchiolitis obliterans (BO) - in 7 pts, heart failure -3 pts, vasculitis -4 pts, tuberculosis or non-tuberculous mycobacterial lung disease (NTMLD) -3 pts, other lung diseases -8 pts.

The comparison of clinical characteristics of the group with $\mathrm{PE}$ and of the remaining patients (Table 2) revealed that VTE history was more frequent in the patients with $\mathrm{PE}$ comparing to non-PE ( $30 \%$ vs. $8.4 \%, p=0.06$ ). Purulent expectoration hasn't been noted in PE, but it was also rarely recorded in the remaining patients (16.8\%). Chest pain was more frequent in PE than in non-PE patients ( $50 \%$ vs. $23.1 \%$ ), nevertheless the difference was not significant. Dyspnea, hemoptysis and increased body temperature were reported with the same frequency in PE and nonPE patients.

$\mathrm{DD}<500 \mathrm{ng} / \mathrm{mL}$ was found in $18 / 153$ patients $(12 \%)$. None of the patients with DD $<500 \mathrm{ng} /$ $\mathrm{mL}$ was diagnosed with PE. The results of the diagnostic algorithm based on RGS, DD and CTA are shown on Figure 1. The diagnostic value of $\mathrm{DD}<500 \mathrm{ng} / \mathrm{mL}$ for the exclusion of PE in low/ intermediate risk patients was high: sensitivity $100 \%$, negative predictive value $-100 \%$.

Median DD value in PE patients was 4500 (525.0-5860.0) $\mathrm{ng} / \mathrm{mL}$ and it was significantly higher than in the remaining patients, in whom median DD was 1356 (105.0-33935.0) ng/mL, p $=0.006$. Elevated plasma DD was found in 135/ $153(88 \%)$ patients: in 10 patients it was observed in the course of PE episode, in the remaining patients - in the course of other lung pathologies listed in Table 3. 


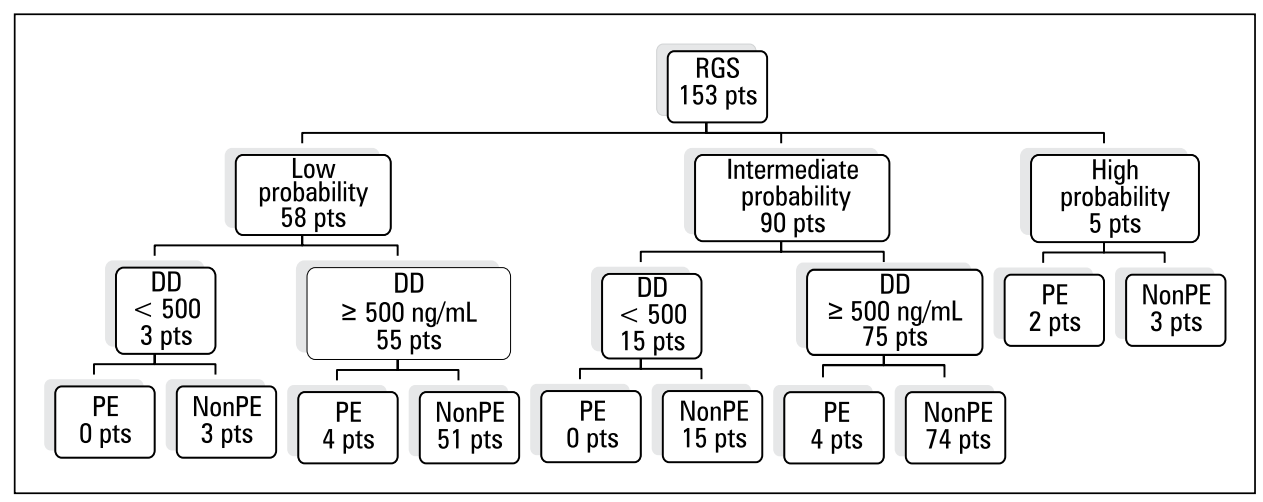

Figure 1. PE recognition based on Revised Geneva Scoring, D-dimer assessment and computed tomography angiography

Table 3. D-dimer (DD) concentration according to clinical diagnosis

\begin{tabular}{|c|c|c|c|c|c|}
\hline Diagnosis & No of pts & $\begin{array}{l}\text { Median DD } \\
{[\mathrm{ng} / \mathrm{ml}]}\end{array}$ & $\begin{array}{l}\text { Range } \\
{[\mathrm{ng} / \mathrm{ml}]}\end{array}$ & $\begin{array}{c}>500 \mathrm{No}(\%) \\
{[\mathrm{ng} / \mathrm{ml}]}\end{array}$ & $\begin{array}{c}P \\
\text { vs. } P E\end{array}$ \\
\hline Neoplastic disease & 45 & 1741.0 & $292.0-28144.0$ & $41(91)$ & 0.03 \\
\hline Pneumonia + tuberculosis, NTMLD & 21 & 1870.0 & $179.0-9266.0$ & $19(90)$ & NS \\
\hline COPD/astma & 15 & 861.1 & $258-2825.24$ & $11(73)$ & 0.001 \\
\hline IPF & 10 & 780.45 & $257.58-1833.0$ & $7(70)$ & 0.003 \\
\hline Other ILD & 19 & 1089.0 & $268.0-5409.4$ & $18(95)$ & 0.02 \\
\hline OP/BO & 7 & 2194.0 & $1106.0-13201.0$ & $7(100)$ & NS \\
\hline $\mathrm{CF}$, bronchiectasis & 11 & 1177.0 & $169.0-33935.0$ & $10(91)$ & 0.02 \\
\hline Hemopthysis, heart failure, others & 11 & 723.0 & $105.0-4361.0$ & $9(82)$ & 0.006 \\
\hline Vasculitis & 4 & 3129.41 & $266.0-6467.0$ & $3(75)$ & NS \\
\hline PE & 10 & 4500.0 & $525.0-5860.0$ & $10(100)$ & \\
\hline Total & 153 & 1466.0 & $105.0-33935.0$ & $135(88)$ & \\
\hline
\end{tabular}

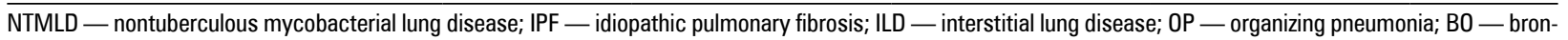
chiolitis obliterans; PE — pulmonary embolism; NS — non-significant

The highest median DD values in non-PE patients were observed in the course of vasculitis (3129.4 ng/mL), OP/BO (2194 ng/mL), CAP (1870 $\mathrm{ng} / \mathrm{mL})$, neoplastic disease $(1741 \mathrm{ng} / \mathrm{mL})$, infective exacerbation of CF or bronchiectasis (1177 ng/ $\mathrm{mL}$ ), the lowest - in COPD/astma exacerbation and in IPF (Table 3, Figure 2). The statistical significance of the obtained results of DD in various lung diseases comparing to PE patients are presented in Table 3.

The comparison of the remaining laboratory parameters between the PE patients and groups with other lung diseases (Table 4) revealed that CRP value was significantly higher in CAP than in $\mathrm{PE}$ patients, median values were $135.4 \mathrm{ng} / \mathrm{mL}$ and $34.46 \mathrm{ng} / \mathrm{mL}$ respectively ( $<0.03$ ) (Figure 3 ).

\section{Discussion}

In the present study, PE based on CTA was recognized in 10 out of 153 patients (7\%) with

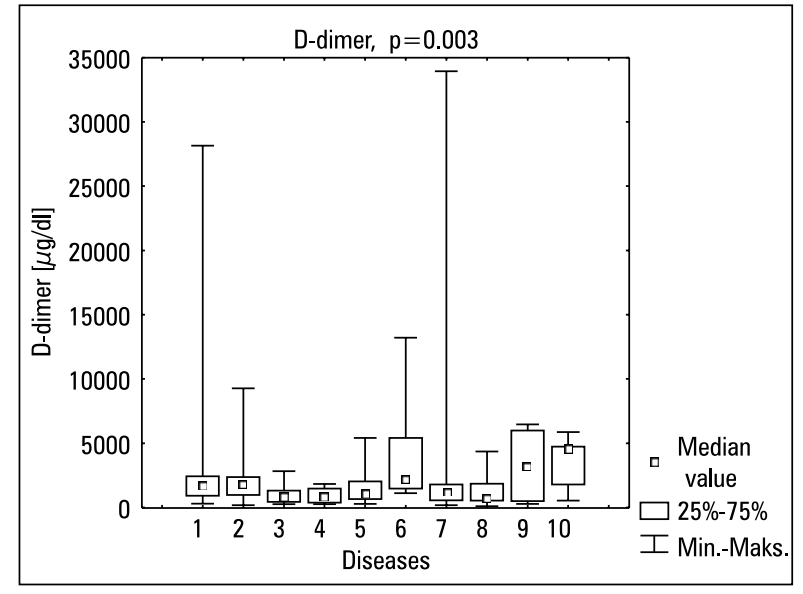

Figure 2. DD-values according to clinical diagnosis

Diseases: 1 - neoplastic disease; 2 - pneumonia, tuberculosis, nontuberculous mycobacterial lung disease; 3 - COPD, astma; 4 idiopathic pulmonary fibrosis; 5 - other interstitial lung diseases; 6 — organizing pneumonia, bronchiolitis obliterans; 7 - cystic fibrosis, bronchiectasis; 8 - hemoptysis, heart failure, others; 9 - vasculitis; 10 - pulmonary embolism. P-values in Table 3 


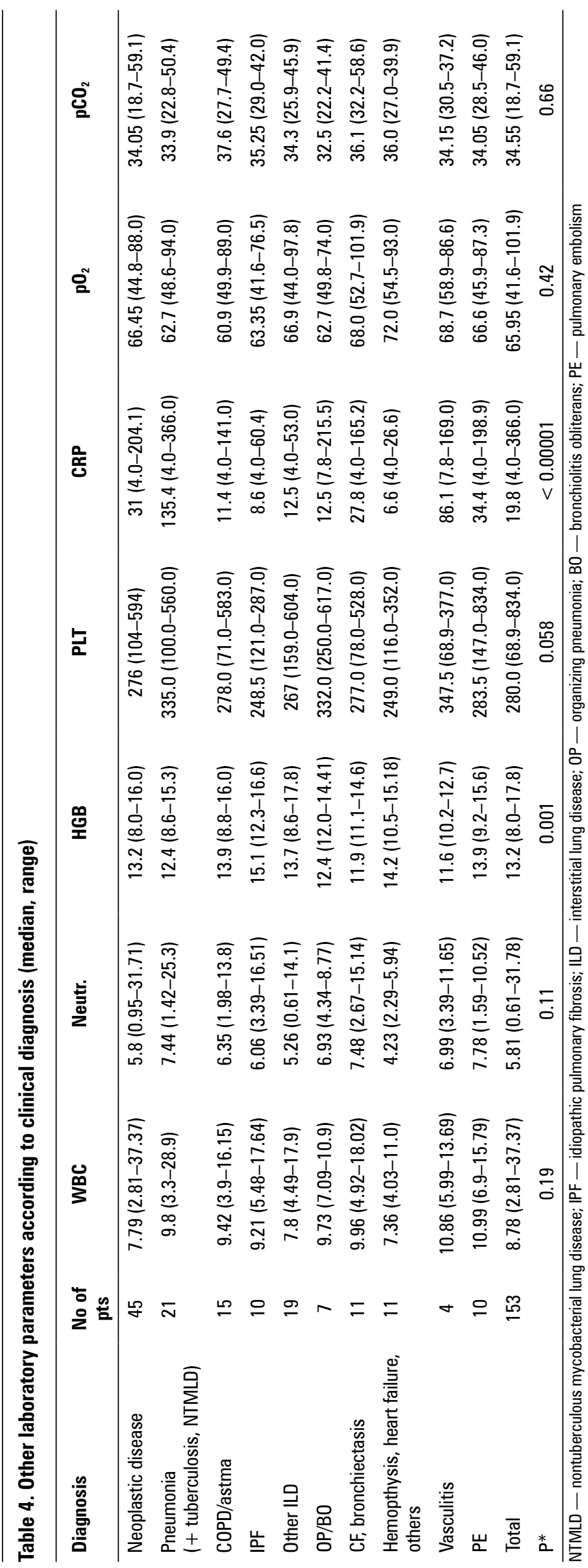




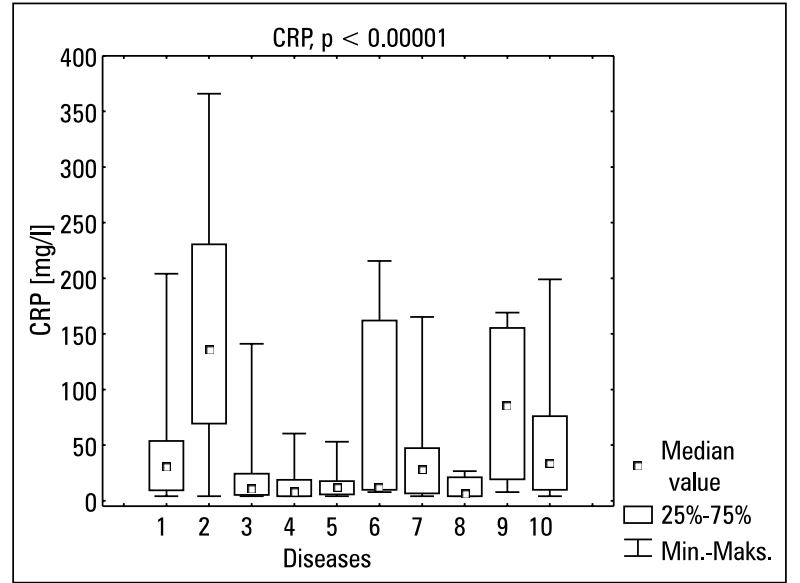

Figure 3. CRP values according to clinical diagnosis

Diseases: 1 - neoplastic disease; 2 - pneumonia, tuberculosis, nontuberculous mycobacterial lung disease; 3 - COPD, astma; 4 - idiopathic pulmonary fibrosis; 5 - other interstitial lung diseases; 6 - organizing pneumonia, bronchiolitis obliterans; 7 - cystic fibrosis, bronchiectasis; 8 - hemoptysis, heart failure, others; 9 - vasculitis; 10 - pulmonary embolism. P-value: 10 vs. $2 p=0.03 ; 10$ vs. $8 p=0.03$

acute respiratory symptoms: 7\% of low PE probability population, $4 \%$ of intermediate probability and $40 \%$ of high probability. The frequency of PE in our material was slightly lower than reported in meta -analysis of Ceriani et al., who found PE confirmed on CTA in $9 \%$ of low probability patients, $26 \%$ — of intermediate probability and $76 \%$ of high probability ones [22]. This difference could be possibly related to the patients characteristics. The population evaluated by RGS in Ceriani's study was composed of the outpatients and our population consisted of patients hospitalized due to acute lung disease.

In our population, the algorithm of VTE probability assessment based on RGS and DD, had a high NPV (100\%), as none of the patients with DD $<500 \mathrm{ng} / \mathrm{mL}$ and low or intermediate probability of $\mathrm{PE}$, was diagnosed with $\mathrm{PE}$. Nevertheless, low DD was found only in $12 \%$ of patients with acute lung disease, therefore its clinical utility in this population was low. The same problem was noted by Fijałkowska et al., who analyzed 619 patients with both acute and chronic lung pathology and found DD elevation in $63 \%$ of patients [23]. Kline et al. found positive DD in $84 \%$ of patients hospitalized on medical and emergency wards with the suspicion of PE, and confirmed PE in 19\% of patients only [24]. The increase of DD cut off value from $500 \mathrm{ng} / \mathrm{mL}$ to $1000 \mathrm{ng} / \mathrm{mL}$, in the patients with RGS lower than 6 points, resulted in the improvement of diagnostic utility of such algorithm, nevertheless it was combined with the slightly increased risk of missing isolated sub-segmental PE [24]. In our group of patients the increase of DD threshold from $500 \mathrm{ng} / \mathrm{mL}$ to $1000 \mathrm{ng} / \mathrm{mL}$ would result in missing one PE case in the patient with intermediate probability of PE.

In the present study, median DD in PE patients was $4500 \mathrm{ng} / \mathrm{mL}$ and it was significantly higher than in non-PE group. The same observation was made by Lippi et al. who found DD > $3000 \mathrm{ng} / \mathrm{mL}$ indicative of VTE in the population of large urban emergency department [25].

The highest median DD values in non-PE lung diseases were observed by us in the course of vasculitis (3129.4 ng/mL), and in OP/BO (2194 $\mathrm{ng} / \mathrm{mL}$ ). Nevertheless it is difficult to comment on this issue, as vasculitis was recognized in 4 patients only and $\mathrm{OP} / \mathrm{BO}$ - in 7 patients. According to our best knowledge no other data concerning this subject has been published.

The frequent cause of DD elevation in the present study was the community acquired pneumonia. Median DD concentration in CAP patients was $1870 \mathrm{ng} / \mathrm{mL}$, the difference between CAP and PE concerning DD value, was not significant. Milbrandt et al. assessed DD concentration (latex immunoassay, cut off value $256 \mathrm{ng} / \mathrm{mL}$ ) in 934 patients hospitalized due to CAP and found DD elevation in $80.6 \%$ of them [26]. Moreover, no substantial changes of DD have been observed during the first 7 days of CAP treatment [26]. The authors suggested that local activation of coagulation, mediated by tissue factor (TF), was the cause of increased DD concentration in pneumonia. The TF, expressed on alveolar macrophages, neutrophils and endothelial cells, might be responsible for systemic coagulopathy during lung infection. The authors found that DD elevation was a negative prognostic factor in CAP: DD 256-1000 ng/mL was combined with 2-3 fold higher mortality rate and DD $>1000 \mathrm{ng} / \mathrm{mL}$ - with 5 fold higher mortality rate [26]. Snijders et al. and Agapakis et al. found DD concentration significantly higher in patients with severe CAP (CURB-65 score $3-5)$ comparing to the others $[27,28]$.

The other frequent cause of DD elevation in our study was neoplastic disease of the chest (lung cancer, thymoma, mesothelioma). Median DD was $1741 \mathrm{ng} / \mathrm{mL}$, the values were significantly lower than in PE patients. Fijałkowska et al. found DD increase in the course of lung cancer in $75 \%$ of patients, with median value of $941 \mathrm{ng} /$ $\mathrm{mL}$ [23]. The histological type of neoplasm and the disease extension are probably influencing DD-concentration [23, 29].

Relatively lower DD values were found by us in the course of asthma or COPD exacerbation. 
According to Sabit et al. hypoxia and systemic inflammation are responsible for pro-coaguable status in COPD, manifesting mainly as the increase of thrombin-antithrombin complex, but not DD concentration [30]. Accordingly, Silva et al. found no difference in DD concentration between stable COPD patients and the control subjects [31]. The increase of DD concentration in COPD may be caused by infective exacerbation. Nevertheless, data from literature indicate that VTE has been responsible for DD increase in $5-38 \%$ of patients with COPD exacerbation [32, 33]. Choi et al. found that $\mathrm{DD} \geq 500 \mathrm{ng} / \mathrm{mL}$ and the absence of symptoms of respiratory infection, were the significant predictors of $\mathrm{PE}$ in the Korean patients with COPD exacerbation [32]. Fruchter et al. found that elevated DD was a reliable prognostic marker for those COPD patients in whom PE was excluded [34].

In our study, median DD in the patients diagnosed with interstitial lung disease was 780.45 $\mathrm{ng} / \mathrm{mL}$ (IPF) and $1089 \mathrm{ng} / \mathrm{mL}$ (non-IPF), and they were significantly lower than in PE patients. There is not much data in literature concerning DD assessment in the patients with ILDs. Bargagli et al. found significantly increased DD in IPF comparing to the controls [35].

Increased DD in the course of ILDs exacerbation may suggest the $\mathrm{PE}$ occurrence. Luo et al. found PE in $26 \%$ of the patients with exacerbation of ILDs, the factors increasing the probability of PE were: dyspnea, palpitations, lower extremity edema, and positive D-dimer [36].

As in majority of the patients in our study PE could not be excluded based on RGS and DD, we tried to find whether the other clinical and/or laboratory parameters would be helpful in predicting or excluding PE. The analysis of clinical parameters revealed that previous history of VTE was more frequent in PE patients. The remaining clinical features such as dyspnea and hemoptysis were not helpful in differential diagnosis. Pleuritic chest pain was more frequent in PE patients comparing to the others, but this difference was not significant.

The analysis of laboratory parameters revealed that CRP value was significantly higher in CAP comparing to PE. In contrast to general population, hypoxemia and hypocapnia, were not indicative for PE in the examined group of patients with acute respiratory symptoms.

\section{Conclusion}

In the examined group of the patients with acute or exacerbated lung diseases low or inter- mediate clinical probability scoring combined with normal DD $(<500 \mathrm{ng} / \mathrm{mL})$ had a high NPV in excluding PE. Nevertheless, such approach was not very effective, as the increased DD (> $500 \mathrm{ng}$ ) $\mathrm{mL}$ ) was noted in $88 \%$ of the examined population. Although median DD was the highest in PE patients, relatively high DD were found also in the course of vasculitis, OP/BO, CAP and neoplastic disease. The probability of PE was higher in the patients with previous history of VTE. High CRP was indicative of CAP.

\section{Conflict of interest}

The authors declare no conflict of interest.

\section{References:}

1. Heit JA. The epidemiology of venous thromboembolism in the community. Arterioscler Thromb Vasc Biol 2008; 28: 370-372.

2. Cohen AT, Agnelli G, Anderson FA et al. Venous thromboembolism (VTE) in Europe. The number of VTE events and associated morbidity and mortality. Thromb Haemost 2007; 98: 756-764.

3. Anderson FA Jr, Spencer FA. Risk factors for venous thromboembolism. Circulation 2003; 107 (suppl. 1): I9-I16.

4. Timp JF, Braekkan SK, Versteeg HH, Cannegieter SC. Epidemiology of cancer associated venous thrombosis. Blood 2013; 122: 1712-1723. doi: 10.1182/blood-2013-04-460121.

5. Khalil J, Bensaid B, Elbacemi H et al. Venous thromboembolism in cancer patients: an underestimated major health problem. World J Surg Oncol 2015; 13: 204. doi: 10.1186/ s12957-015-0592-8.

6. Cavailles A, Brinchault-Rabin G, Dixmier A et al. Comorbidities of COPD. Eur Respir Rev 2013; 22: 454-475. doi: 10.1183/ /09059180.00008612.

7. Majoor CJ, Kamphuisen PW, Zwinderman AH et al. Risk of deep vein thrombosis and pulmonary embolism in asthma. Eur Respir J 2013; 42: 655-661. doi: 10.1183/09031936.00150312.

8. Dalleywater W, Powell HA, Fogarty AW, Hubbard RB, Navaratnam V. Venous thromboembolism in people with idiopathic pulmonary fibrosis: a population-based study. Eur Respir J 2014; 44: 1714-1715. doi: 10.1183/09031936.00099614.

9. Swigris JJ, Olson AL, Huie TJ et al. Increased risk of pulmonary embolism among US decedents with sarcoidosis from 1988 to 2007. Chest 2011; 140: 1261-1266. doi: 10.1378/chest.11-0324.

10. Vorselaars A, Snijder RJ, Grutters JC. Increased number of pulmonary embolisms in sarcoidosis patients. Chest 2012; 141: 826-827. doi: 10.1378/chest.11-2514.

11. Wytyczne ESC dotyczące rozpoznawania i postępowania w ostrej zatorowości płucnej w 2014 roku. Kardiol Pol 2014; 72: 997-1053. doi: 10.5603/KP.2014.0211.

12. Carrier M, Righini M, Djurabi RK et al. VIDAS D-dimer in combination with clinical pre-test probability to rule out pulmonary embolism. A systematic review of management outcome studies. Thromb Haemost 2009; 101: 886-892.

13. Jeremiah ZA, Adias TC, Opiah M, George SP, Mgbere O, Essien EJ. Elevation in D-dimer concentrations is positively correlated with gestation in normal uncomplicated pregnancy. Int J Womens Health 2012; 4: 437-443. doi: 10.2147/IJWH.S32655.

14. Pulivarthi S, Gurram MK. Effectiveness of D-dimer as a screening test for venous thromboembolism: the update. North Am J Med Sci 2014; 6: 491-499. doi: 10.4103/19472714.143278.

15. Righini M, Le Gal G, De Lucia S et al. Clinical usefulness of D-dimer testing in cancer patients with suspected pulmonary embolism. Thromb Haemost 2006; 95: 715-719.

16. Crop MJ, Siemes C, Berendes P, van der Straaten F, Willemsen $\mathrm{S}$, Levin MD. Influence of C-reactive protein levels and age on the value of D-dimer in diagnosing pulmonary embolism. Eur J Haematol 2014; 92: 147-155. doi: 10.1111/ejh.12218. 
17. Haase C, Joergensen M, Ellervik C, Joergensen MK, Bathum L. Age and sex-dependent reference intervals for D-dimer: evidence for a marked increase by age. Thromb Res 2013; 132: 676-680. doi: 10.1016/j.thromres.2013.09.033.

18. Schouten HJ, Geersing GJ, Koek HL et al. Diagnostic accuracy of conventional or age adjusted D-dimer cut off values in older patients with suspected venous thromboembolism: systematic review and metaanalysis. BMJ 2013; 346: f2492. doi: 10.1136/bmj.f2492.

19. Righini M, Van Es J, den Exter PL et al. Age adjusted D-dimer cut off levels to rule out pulmonary embolism: the ADJUST-PE study. JAMA 2014; 311: 1117-1124. doi: 10.1001/ jama.2014.2135.

20. Woller SC, Stevens SM, Adams DM et al. Assessment of the safety and efficiency of using an age-adjusted D-dimer threshold to exclude suspected pulmonary embolism. Chest 2014; 146: 1444-1451. doi: 10.1378/chest.13-2386.

21. Lindner G, Funk GC, Pfortmueller CA et al. D-dimer to rule out pulmonary embolism in renal insufficiency. Am J Med 2014; 127: 343-347. doi: 10.1016/j.amjmed.2013.12.003.

22. Ceriani E, Combescure C, Le Gal G et al. Clinical prediction rules for pulmonary embolism: a systematic review and meta-analysis. J Thromb Haemost 2010; 8: 957-970. doi: 10.1111/j.1538-7836.2010.03801.x

23. Fijałkowska A, Wiatr E, Kurzyna M et al. Normal D-dimer concentration in hospitalized patients with lung diseases. Pneumonol Alergol Pol 2012; 80: 101-108.

24. Kline JA, Hogg MM, Courtney DM, Miller CD, Jones AE, Smithline HA. D-dimer threshold increase with pretest probability unlikely for pulmonary embolism to decrease unnecessary computerized tomographic pulmonary angiography. J Thromb Heamost 2012; 10: 572-581. doi: 10.1111/j. 1538-7836.2012.04647.x.

25. Lippi G, Bonfanti L, Saccenti C, Cervellin G. Causes of elevated D-dimer in patients admitted to a large urban emergency department. Eur J Intern Med 2014; 25: 45-48. doi: 10.1016/j. ejim.2013.07.012.

26. Milbrandt EB, Reade MC, Lee M et al. Prevalence and significance of coagulation abnormalities in community-acquired pneumonia. Mol Med 2009; 15: 438-445. doi: 10.2119/molmed.2009.00091.
27. Snijders D, Schoorl M, Scoorl M, Bartels PC, van der Werf TS, Boersma WG. D-dimer levels in assessing severity and clinical outcome in patients with community-acquired pneumonia. A secondary analysis of randomised clinical trial. Eur J Intern Med 2012; 23: 436-441. doi: 10.1016/j.ejim.2011.10.019.

28. Agapakis DI, Tsantilas D, Psarris P et al. Coagulation and inflammation biomarkers may help predict the severity of community-acquired pneumonia. Respirology 2010; 15: 796-803. doi: 10.1111/j.1440-1843.2010.01773.x.

29. Chen F, Wang MJ, Li J et al. Plasma D-dimer value as a predictor of malignant lymph node involvement in operable nonsmall cell lung cancer. Tumor Biol 2015 [ahead of print].

30. Sabit R, Thomas P, Shale DJ, Collins P, Linnane SJ. The effects of hypoxia on markers of coagulation and systemic inflammation in patients with COPD. Chest 2010; 138: 47-51. doi: 10.1378/chest.09-2764.

31. Silva DR, Coelho AC, Gazzana MB, Barreto M, Knorst MM. D-dimer levels in stable COPD patients: a case-control study. COPD 2012; 9: 426-431. doi: 10.3109/15412555.2012.683840.

32. Choi KJ, Cha SI, Shin KM et al. Prevalence and predictors of pulmonary embolism in Korean patients with exacerbation of chronic obstructive pulmonary disease. Respiration 2013; 85: 203-209. doi: 10.1159/000335904.

33. Akpinar EE, Hosgun D, Doganay B, Atac GK, Gulhan M. Should the cut-off value of D-dimer be elevated to exclude pulmonary embolism in acute exacerbation of COPD? J Thorac Dis 2013; 5: 430-434. doi: 10.3978/j.issn.2072-1439.2013.07.34.

34. Fruchter O, Yigla M, Kramer MR. D-dimer as a prognostic biomarker for mortality in chronic obstructive pulmonary disease exacerbation. Am J Med Sci 2015; 349: 29-35. doi: 10.1097/ MAJ.0000000000000332.

35. Bargagli E, Madioni C, Bianchi N, Refini RM, Cappelli R, Rottoli P. Serum analysis of coagulation factors in IPF and NSIP. Inflammation 2014; 37: 10-16. doi: 10.1007/s10753013-9706-z.

36. Luo Q, Xie J, Han Q et al. Prevalence of venous thromboembolic events and diagnostic performance of the Wells score and revised Geneva scores for pulmonary embolism in patients with interstitial lung disease: a prospective study. Heart Lung Circ 2014; 23: 778-785. doi: 10.1016/j.hlc.2014.02.014. 